\title{
Dynamics of nevus development implicate cell cooperation in the growth arrest of transformed melanocytes
}

Rolando Ruiz-Vega ${ }^{1,2}$, Chi-Fen Chen ${ }^{3}$, Emaad Razzak ${ }^{1}$, Priya Vasudeva ${ }^{3}$, Tatiana B. Krasieva ${ }^{4}$, Jessica Shiu ${ }^{3}$, Michael G. Caldwell ${ }^{1}$, Huaming Yan ${ }^{5}$, John Lowengrub ${ }^{1,5}$, Anand Ganesan ${ }^{1,3,6}$, Arthur D. Lander ${ }^{*} 1,2$

1. Center for Complex Biological Systems, University of California Irvine, Irvine CA, 92697, USA.

2. Department of Developmental and Cell Biology, University of California Irvine, Irvine CA, 92697, USA.

3. Department of Dermatology, University of California Irvine, Irvine CA, 92697, USA.

4. Beckman Laser Institute, University of California Irvine, Irvine CA, 92697, USA.

5. Department of Mathematics, University of California Irvine, Irvine CA, 92697, USA.

6. Department of Biological Chemistry, University of California Irvine, Irvine CA, 92697, USA.

*Correspondence: adlander@uci.edu

Keywords:

Nevi, melanocytes, Braf mutation, oncogene induced senescence, nevus mouse model, skin, nevus growth arrest, systems biology, clonal dynamics, pigment, live mouse imaging, SASP, senescence

Short Title: Cooperative dynamics in melanocyte growth arrest 


\begin{abstract}
1 Abstract
2 Mutational activation of the BRAF proto-oncogene in melanocytes reliably produces benign nevi

3 (pigmented "moles"), yet the same change is the most common driver mutation in melanoma. The

4 reason nevi stop growing, and do not progress to melanoma, is widely attributed to a cell-

5 autonomous process of "oncogene-induced senescence". Using a mouse model of Braf-driven

6 nevus formation, analyzing both proliferative dynamics and single-cell gene expression, we found

7 no evidence that nevus cells are senescent, either compared with other skin cells, or other

8 melanocytes. We also found that nevus size distributions could not be fit by any simple cell-

9 autonomous model of growth arrest, yet were easily fit by models based on collective cell

10 behavior, e.g. in which arresting cells release an arrest-promoting factor. We suggest that nevus

11 growth arrest is more likely related to the cell interactions that mediate size control in normal

12 tissues, than to any cell-autonomous, "oncogene-induced" program of senescence.

INTRODUCTION

Activating BRAF mutations (e.g. BRAF ${ }^{\mathrm{V} 600 \mathrm{E}}$ ) are the most common oncogenic mutations in melanoma, seen in about $66 \%$ of cases (Davies et al., 2002). Curiously, the same mutation is found in $89 \%$ of melanocytic nevi (Pollock et al., 2003)—the benign, pigmented "moles" found on

18 the skin of most individuals. In animal studies, melanocyte-specific expression of BRAF ${ }^{\mathrm{V} 600 \mathrm{E}}$ efficiently produces nevi, but only very rarely melanoma (Dankort et al., 2009; Dhomen et al., 2009; Patton et al., 2005). The widely-accepted explanation is that transformed melanocytes undergo oncogene-induced senescence (OIS), arresting proliferation before additional oncogenic events can occur (e.g. Bennett, 2003; Huang et al., 2017; Kaplon et al., 2014; Michaloglou et al., 23 2005).

Nevus melanocytes are indeed growth-arrested, but the assumption that OIS is the cause remains untested, in part because of a lack of criteria to rigorously define OIS in vivo (Damsky \& 26 Bosenberg, 2017). Initially studied as a consequence of forced expression of oncogenes in cell cultures (Serrano et al., 1997), OIS has come to be seen as a distinctive cellular stress response characterized by a phenotype of growth arrest, morphological and metabolic changes, chromatin alterations, and secretion of growth factors, chemokines, cytokines and proteases (Campisi \& d'Adda di Fagagna, 2007; Gorgoulis et al., 2019; Ito et al., 2017; Kuilman et al., 2010).

Given an abundance of "hallmarks" of senescence, one might think that recognizing this cell 33 other growth-arrested cell states. Phenotypes once thought to be "gold standards", such as 
34 expression of lysosomal beta-galactosidase, cyclin-dependent kinase inhibitors, or p53, 35 commonly mark only subsets of senescent cells (Wiley et al., 2017), as well as non-senescent

36 cells (Tran et al., 2012). Moreover, observations of supposedly senescent cells resuming 37 proliferation (e.g. Beausejour et al., 2003), imply that permanent cell cycle exit cannot be used as 38 a distinguishing feature. In vivo senescence, as a result, is currently somewhat of a Gestalt 39 diagnosis, i.e. assessed by a collection of traits, no subset of which is necessary or sufficient. Yet 40 there is no clear consensus on which traits are best to assess, and recent meta-analyses of gene 41 expression suggest that some of the most commonly assessed features are not "core" to 42 senescence at all (Hernandez-Segura et al., 2017).

43 The reason it is important to clarify how BRAF-transformed nevus melanocytes stop growing 44 is that it shapes how we think about the origins of melanoma. OIS is usually portrayed in cell45 intrinsic terms: oncogene expression within a transformed cell produces a stress within that cell, 46 which triggers it to senesce. Even those who acknowledge a possible role for paracrine signals 47 (Acosta et al., 2013; Elzi et al., 2012; Ito et al., 2017; Wajapeyee et al., 2008) still portray the 48 process as something initiated and orchestrated by cell-autonomous responses to oncogenes. 49 This naturally leads to an approach to melanoma prevention and treatment that focuses on 50 understanding how oncogenes derange intracellular processes; how those derangements elicit 51 stress responses; and what might enable cancer cells to circumvent those responses (e.g. 52 Bennett, 2003; Damsky \& Bosenberg, 2017; Vredeveld et al., 2012; Yu et al., 2018). In contrast, 53 as we argue below, it is possible that the growth arrest displayed by nevus melanocytes has little 54 to do with oncogene-induced stress, and may have more to do with networks of cell-cell communication that are characteristic of melanocytes, independent of whether they are

56 transformed. In this case, the most effective path to understanding how to prevent or treat 57 melanoma could be to better elucidate the normal physiology of melanocytes in their environment.

Here, we investigate the details of nevus growth arrest in a model in which melanocytespecific Braf activation generates hundreds of nevi on the skin of mice (Dankort et al., 2009). By examining both single-cell transcriptomes and the dynamics of growth arrest in nevus-associated melanocytes, we make two key observations: First, patterns of gene expression in arrested nevus

62 melanocytes fail to identify them as any more senescent than other skin cells or normal 63 melanocytes, arguing against a primary role for any form of senescence in their arrest. Second, 64 the timing and statistics of nevus formation effectively argue against any relatively simple cell65 autonomous process as being the cause of growth arrest. Ultimately, we propose a model in 66 which arrest is driven not by oncogene stress, but by feedback mechanisms similar to those 
commonly involved in normal tissue homeostasis.

68 RESULTS

\section{Dynamics of nevus growth}

70 Characterizing the dynamics of nevus growth and arrest requires observing nevi that started

71 growing at known times. We took advantage of a mouse model in which Cre-mediated

72 recombination introduces the activating V600E mutation into the endogenous Braf locus. When

73 crossed onto a background carrying a Tyr::CreER transgene, the mice acquire the Braf $f^{1 / 600 E}$

74 mutation only in cells of the melanocytic lineage, and only after Cre activation by 4-

75 hydroxytamoxifen (4-OHT), applied either systemically or through painting on the skin.

76 As shown previously (Dankort et al., 2009), 4-OHT treatment of these mice leads to development of numerous pigmented nevi. Visualization of nevi is hindered, however, by the strong pigmentation in hair follicles which, except at microscopic resolution, can be difficult to distinguish from nevi. One way to circumvent this difficulty is to observe nevi only during the telogen phase of the hair cycle, when follicle-associated pigment is not present (conveniently, synchronization of hair cycles may be maintained on a large patch of skin through depilation).

As shown in Figure 1, in mice whose back skin was treated with topical 4-OHT at postnatal day 2 (P2), P3 and P4, nevi were apparent macroscopically at telogen (P50; Fig. 1A). Liveimaging, using multi-photon microscopy (MPM; (Saager et al., 2015)), revealed that, like human nevi, mouse nevi consist of scattered nests of pigment-containing cells (Fig. 1B). Nevi could also be visualized post-mortem, using a dissecting microscope, on the undersurface of pieces of telogen-stage back skin (Fig. 1C).

An alternate approach to visualization that did not require hair synchronization was to generate nevi by painting 4-OHT on glabrous (hairless) skin, such as the ventral surface of the paw, permitting tracking of individual nevi on a daily basis. As shown in Fig. 1D, when forepaws

91 were treated with 4-OHT from P2 through P4, tiny nevi could be detected as early as P6. Serial 92 observation indicated that most nevi reach a maximum size somewhere between P16 and P21

93 (Fig. 1D and S1A). This suggests that, in the mouse, Braf ${ }^{1 / 600 E}$-transformed melanocytes arrest 94 within 2-3 weeks. To confirm this, we used BrdU labeling to monitor DNA synthesis. Because 95 melanin readily obscures immunohistochemical signals, these experiments were done in an 96 albino (unpigmented) genetic background, using premelanosome protein (Pmel) staining to 

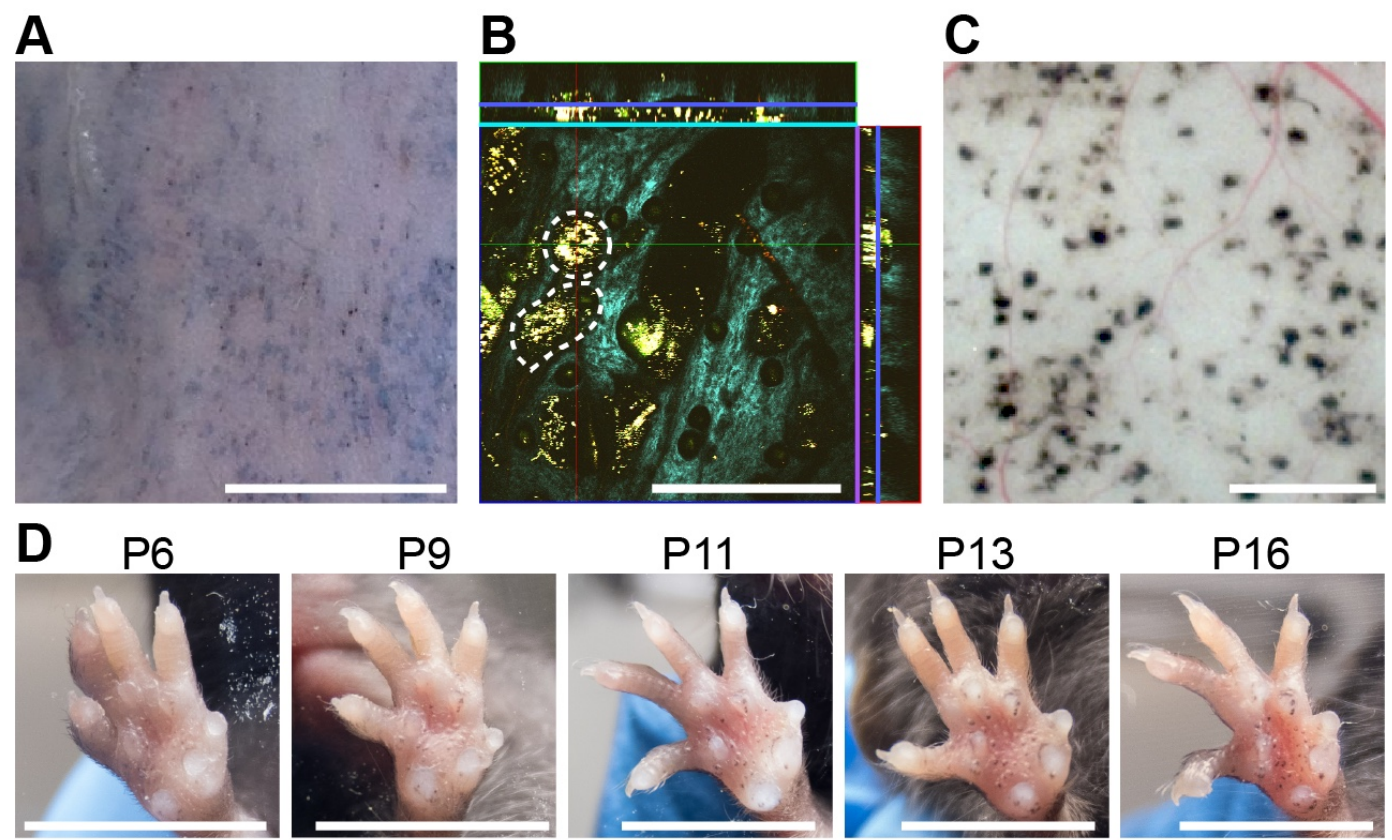

P16
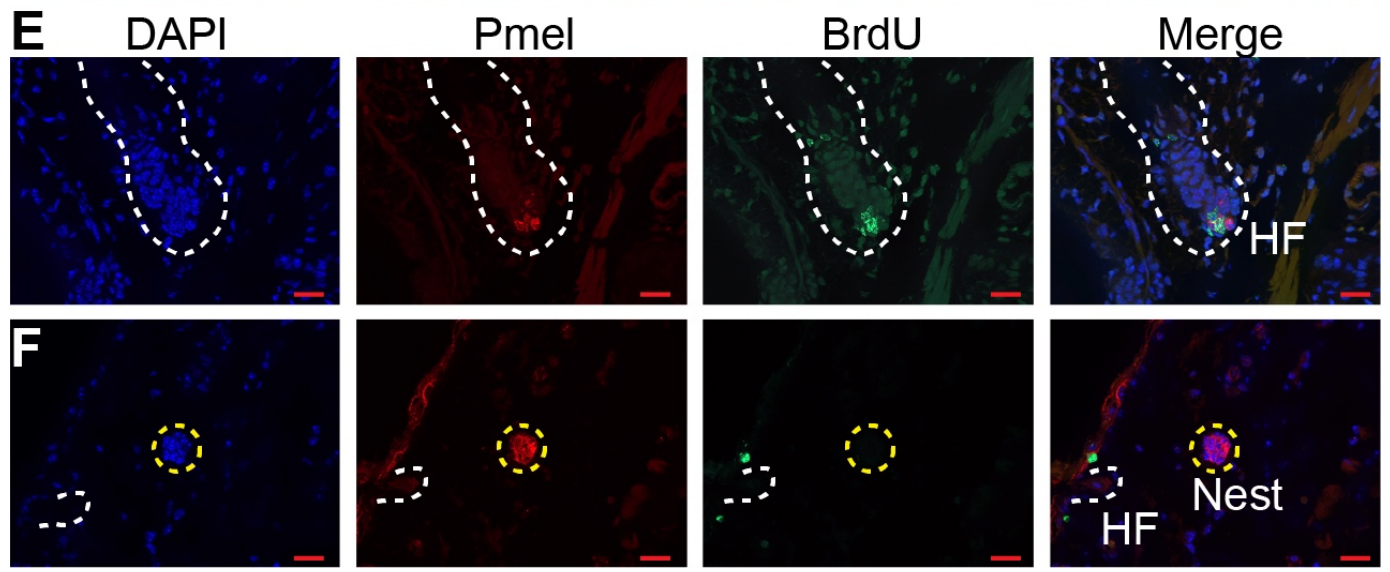

Figure 1. Dynamics of nevus growth. A-D. Visualization of nevi on Braf ${ }^{\mathrm{V} 600 \mathrm{E}}$ mice. (A) Live imaging of back skin at telogen stage (P50), following hair depilation. Scale bar $=5 \mathrm{~mm}$. (B) Live imaging of a sample like that in panel A using multiphoton microscopy. The central square is an en face view of the skin ( $x-y$ plane), while rectangles above and to the right are cross-sections $(x-z$ and $y-z$ planes, respectively, with blue lines marking the location of the central image). Melanin autofluorescence appears yellow, second harmonic generation of collagen is cyan, and keratin autofluorescence is green. Dashing outlines dermal melanocyte nests. Scale bar $=318 \mu \mathrm{m}$. (C) Appearance of nevi on the undersurface of back skin (at P21). Scale bar $=1 \mathrm{~mm}$. (D) Nevus development on the ventral (glabrous) surface of the paw. Images of a single paw were taken at the indicated ages. Scale bar $=0.5 \mathrm{~cm}$. F. Assessment of melanocyte proliferation. Sections are from albino wildtype (E) and $\operatorname{Braf}^{\mathrm{V} 600 \mathrm{E}}(\mathrm{F})$ skin at P21. Melanocytes were identified by premelanosome protein (Pmel) immunohistochemistry and proliferation assessed by BrdU incorporation. Wildtype hair follicle (HF) melanocytes $(E)$ incorporate BrdU whereas nevus melanocytes $(F)$ do not. Scale bar $=20 \mu \mathrm{m}$. 
identify melanocytes. As shown in Fig. 1F, albino mice generate nests similar to those seen in pigmented mice. In such animals, BrdU readily incorporated into hair follicle melanocytes (Fig. 1E, S1B), whereas by p21 nests within nevi were uniformly negative for BrdU, implying growth arrest (Fig. 1F, S1C).

102 The conclusion that Braf-induced nevi are already growth-arrested by P21 agrees with the 103 reports of others (Damsky \& Bosenberg, 2017), and is lent further support by time course 104 measurements of nest size by MPM (Fig. 1C), which show that nest size distributions change 105 insignificantly between P21 and P50 (Fig. S4A-B).

\section{Do nevi undergo "oncogene-induced senescence"?}

108 As discussed above, senescence is usually accompanied by distinctive gene expression. 109 Various gene expression "signatures" have been developed to help investigators identify 110 senescent cells and distinguish them from cells that have become growth arrested by other processes. We considered several of these (Data S1):

1) A set of genes encoding the most commonly considered "hallmarks" of senescence, i.e. p53, Rb, lysosomal beta-galactosidase, H2AX, and three cyclin-dependent-kinase inhibitors (“Classical”, 7 genes (Campisi \& d'Adda di Fagagna, 2007; Collado \& Serrano, 2006));

2) A gene signature that distinguishes cultured human fibroblasts growth arrested by BRAFtransformation from quiescent fibroblasts (“Kuilman”, 21 genes (Kuilman et al., 2008))

3) Results of a meta-analysis (Hernandez-Segura et al., 2017)) of publications on fibroblasts, melanocytes, and astrocytes, comparing senescence (induced by multiple different stresses) with

119 quiescence, yielding "universal" signatures of genes that are up- and down-regulated specifically 120 in senescence ("Universal Up", 31 genes, and "Universal Down", 23 genes) as well as signatures 121 of genes specifically up- or down-regulated by senescence induced in melanocytes ("Melanocyte 122 Up", 397 genes and "Melanocyte Down", 135 genes).

123 4); The most statistically significant genes in a recent meta-analysis (Chatsirisupachai et al., 124 2019) of 20 replicative senescence microarray datasets from the Gene Expression Omnibus 125 (“Chatsirisupachai Up”, 237 genes and “Chatsirisupachai Down”, 244 genes).

126 5) A list of genes characteristic of the "Senescence-Associated Secretory Phenotype" 127 ("SASP", 81 genes), compiled from 38 literature references (for citations see Data S1).

128 To determine whether any of these proposed signatures fits nevus melanocytes, we 129 performed single cell RNA-sequencing on dissociated cells from the back skin of nevus-bearing 
130 mice at both P30 and P50 (i.e. after nevi have stopped growing), using wildtype skin as a control.

131 Using known cell-type marker genes (Fig. S2A-B), we identified 14 different cell types in the skin,

132 including melanocytes (Fig. 2A). Unsupervised clustering further sub-divided the melanocytes

133 into four groups (Fig. 2B): Two of them, Mel 0 and Mel 1, were composed of cells found only in

134 nevus-bearing, and not wild-type, skin (Fig. 2C); they are highly similar in gene expression,

A

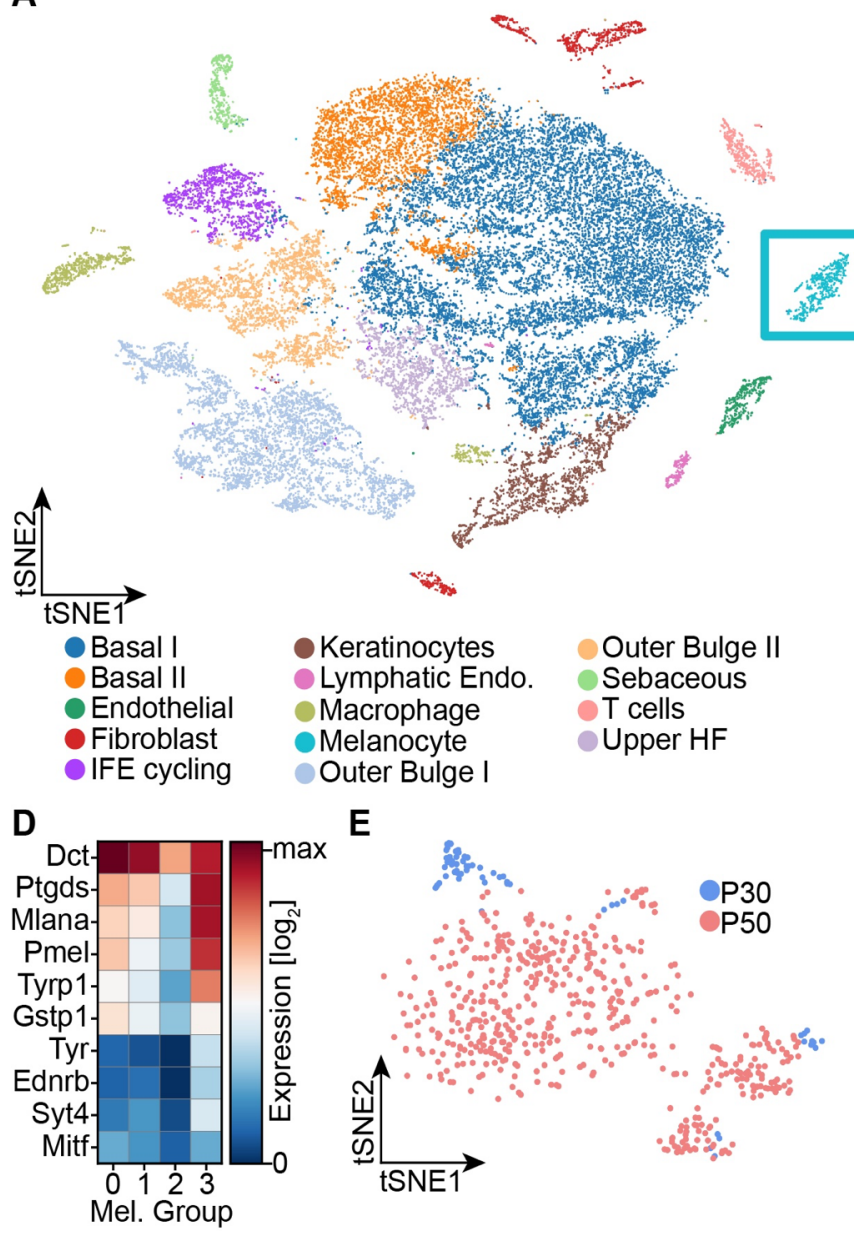

B

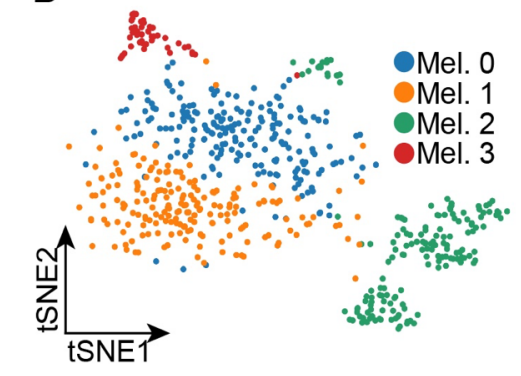

C

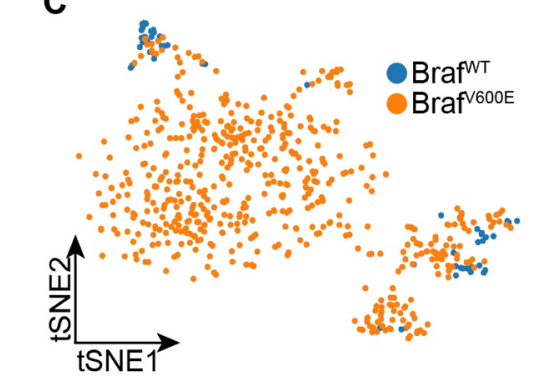

$\mathbf{F}$

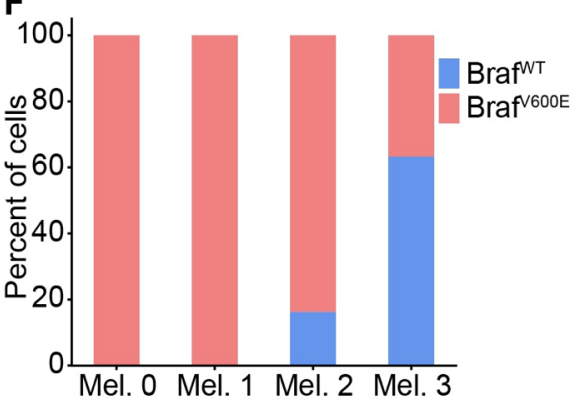

Figure 2. Single cell RNA sequencing of mouse dorsal skin to transcriptionally characterize melanocytes. A. Skin cell types are visualized with tSNE (cells $=35,141)$ from mice at P30 $\left(n\left[B\right.\right.$ Braf $\left.^{W T}\right]$ $=2$ mice, $n\left[\mathrm{Braf}^{\mathrm{V} 600 \mathrm{E}}\right]=2$ mice $)$ and $\mathrm{P} 50\left(\mathrm{n}\left[\mathrm{Braf}^{\mathrm{WT}}\right]=3\right.$ mice, $\mathrm{n}\left[\mathrm{Braf}{ }^{\mathrm{V600E}}\right]=3$ mice $)$. Melanocytes are outlined with a blue box. B. Subclustering of melanocytes $(n=609)$ and visualized on a tSNE plot. Four clusters were identified. C. Visualization of melanocytes based on their genotype on a tSNE plot. D. A heat map of different genes involved in pigmentation. Each cluster expresses these genes at different levels. E. Visualization of melanocytes based on their age on a tSNE plot. F. Quantification of melanocytes in each cluster based on their genotype BRAF wild-type or mutant mice. 
135 primarily differing in having a slightly lower level of pigment gene expression in Mel 1 versus Mel 1360 (Fig. 2D). We identify them as the "nevus melanocytes", because they are seen only when nevi 137 are present, and are by far the predominant melanocyte population in such animals.

138 Mel 2 cells express the lowest levels of pigmentation genes (Fig. 2D), and are seen in both 139 genotypes (Fig. 2C) at all stages (although expanded in number in nevus-bearing animals (Fig. $1402 \mathrm{~F})$ ). Their pattern of gene expression bears a strong resemblance to one recently published for 141 melanocyte stem cells isolated from telogen-stage hair follicles (Zhang et al., 2020). In particular, 142 they express $C d 34$, which has been proposed to be a marker for bulge-associated melanocyte 143 stem cells (Joshi et al., 2019).

144 Finally, cells of cluster Mel 3, which express the highest levels of pigment genes (Fig. 2D), are found in both mutant and wildtype mice, but only at the P30 time point (Fig. 2E-F). We thus identify them as mature hair follicle melanocytes, as such cells are present exclusively during anagen phase of the hair cycle (P30), and disappear during telogen (P50).

Because gene signatures are based on the idea of up- and down-regulation of expression relative to some baseline state, to test whether nevus melanocytes fit a known signature it is necessary to have comparison transcriptomes. We made two types of comparisons: nevus melanocytes versus every other cell type in the skin (which, with the possible exception of mature keratinocytes, we would not expect to be senescent); and the four melanocyte sub-clusters (two of which are nevus-associated and two of which are not) versus each other. In each case we computed average expression for each gene in every cell type or cluster, together with a standard error of the mean as a measure of dispersion. Expression values were then normalized to average expression across all of the cells being compared (i.e. all skin cells, or all melanocytes, 157 depending on which comparison was being done) and $\log _{2}$-transformed, so that positive values 158 signify upregulation (relative to the average for that gene), and negative downregulation. Gene 159 expression was then visualized using heat maps (Fig. 3A, S3, with positive values in blue and 160 negative in red). Because gene expression levels inferred from single cell RNA sequencing tend 161 to be noisy, particularly for genes with low expression, we ranked all genes by their minimum level 162 of noise (i.e. normalized standard error of the mean in the least noisy cell type), and used this 163 value ("n-SEM", which is also presented graphically as a bar to the right of each heatmap) to sort 164 gene lists, so that maps vary from most to least reliable as one goes from top to bottom.

165 Figure 3A shows the results for the "Classical" and "Universal Up" signatures (heat maps for 166 the other signatures are shown in Figure S3). Here we see no strong enrichment of blue over red 167 signals in nevus melanocytes, nor in most other cells. When compared with whole skin, using 
168 the "Classical" signature, only Cdkn2a stands out as strongly upregulated in nevus melanocytes,

169 but it is similarly upregulated in skin fibroblasts (it also has the noisiest data among genes in the

170 signature). With the "Universal Up" signature, more genes are downregulated than upregulated

171 in nevus melanocytes. To quantify such impressions, we summed the $\log _{2}$-transformed data in

172 each column in every heat map, producing the bar graphs in Figure 3B. We reasoned that

173 summation of log-transformed data would emphasize consistent trends in the data while

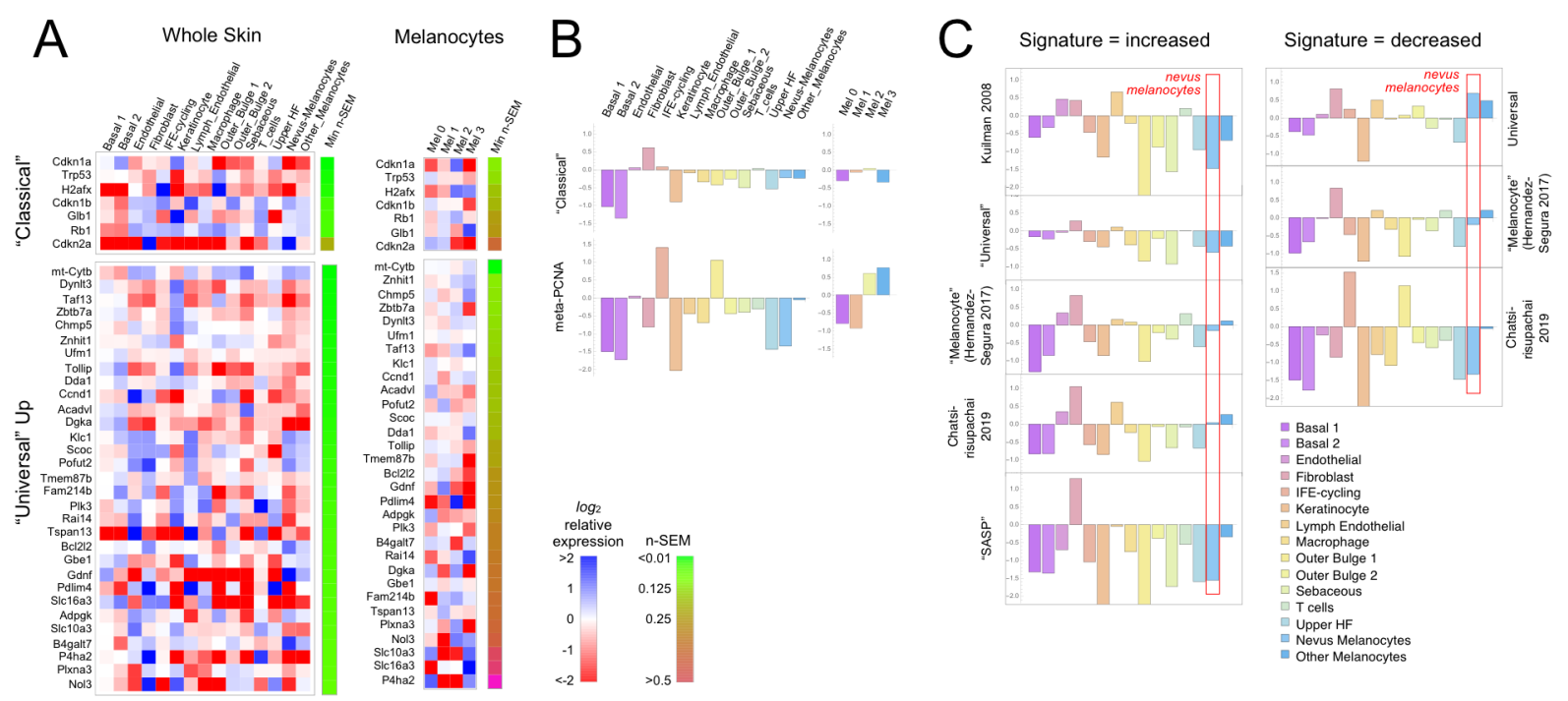

Figure 3. Gene expression fails to identify nevus melanocytes as senescent. Transcriptomes of clusters identified in Fig. 2 were compared with proposed "signatures" of senescence. A. Gene expression data for clusters in Fig. $2 \mathrm{~A}$ and 2B were averaged by cluster and, for each gene, expressed as a ratio to the average expression level of that gene in the entire skin sample ("Whole Skin") or just the melanocyte clusters ("Melanocytes"). The heat map displays the logarithm of that ratio, with blue representing upregulation and red downregulation, relative to the appropriate average. Two proposed signatures for genes upregulated in senescence ("Classical" and "Universal Up") are shown (For other signatures, see Fig. S4). Gene lists have been sorted by the minimum gene expression variability within the least variable cluster (green-brown bar). B. The "Classical" heatmaps in panel A are summarized as a bar graph displaying the sum of the log-transformed data. Also shown are summary results for a proposed signature of proliferation, "meta-PCNA", which clearly distinguishes between cell types expected to be proliferative and non-proliferative (in normal skin). The "Classical" senescence signature fails to identify nevus melanocytes (Mel 0 and Mel 1) as senescent, especially when compared with other cell types or other melanocytes. C. Extension of the analysis in panel $B$ to eight additional signatures. 
174 suppressing effects of noise (random positive and negative variation would tend to cancel out).

175 The results suggest that skin fibroblasts better fit the "Classical" senescent signature than any 176 skin cell type, including nevus melanocytes, or indeed melanocytes of any cluster. As a control-

177 to demonstrate the ability of this approach to correctly associate cell types with gene signatures178 we analyzed the same data using a signature of cell proliferation, "meta-PCNA", that represents 179129 human genes most positively correlated with proliferation marker PCNA in a compendium of 180 normal tissues (Venet et al., 2011). As shown in Fig. 3B (also see Fig. S3), this signature (122 181 genes of which had unambiguous mouse orthologs; Data S1) identified two keratinocyte 182 populations ("IFE-cycling" and "Outer Bulge 1") as highly proliferative (in agreement with (Joost 183 et al., 2020)), and mature (postmitotic) keratinocytes as non-proliferative. Importantly, it also 184 correctly identified nevus melanocytes as non-proliferative-and other melanocytes as 185 proliferative-in agreement with Fig. 1E-F.

186 Figures $3 \mathrm{C}$ and S3 extend this analysis to the remaining eight potential signatures of 187 senescence (five consisting of genes that are upregulated; three of genes that are 188 downregulated). In five of the eight cases, nevus melanocytes rank as less senescent than the 189 average skin cell; in two of the cases nevus melanocytes are about average. In only one case 190 ("Chatsirisupachai Down") does nevus melanocyte gene expression go in the predicted direction 191 for senescence. However, the Chatsirisupachai signatures had not been curated to remove 192 genes associated simply with proliferation/quiescence (Chatsirisupachai et al., 2019), and 193 inspection of the "Chatsirisupachai Down" gene list shows that 61 of its 250 genes are shared 194 with the 129-gene meta-PCNA signature; i.e., it is more likely a signature of proliferation than 195 "non-senescence" (note the strong similarity between the "Chatsirisupachai Down" bar graph in 196 Fig. 3C and the meta-PCNA graph in Fig. 3B).

197 Together these data do not support the view that any sort of senescence-oncogene-induced 198 or otherwise-is characteristic of nevus melanocytes and therefore a possible cause of their 199 growth arrest.

\section{Does a cell autonomous process arrest nevi?}

201 As discussed above, OIS is usually presented as a cell-autonomous process [e.g. (Dankort et 202 al., 2009; Dhomen et al., 2009; Michaloglou et al., 2005; Serrano et al., 1997)]. The simplest cell203 autonomous process that one might imagine is a probabilistic switch: Once oncogene activation 204 commences, cells arrest with a fixed probability (per time or per cell cycle). Regardless of the 205 molecular details, such a model makes distinctive predictions about clonal dynamics.

206 Consider the clonal descendants of a single oncogene-transformed founder cell. For any 
value of the per-cell-cycle senescence probability (which we denote here as " $s$ "), how many cells should we expect that clone to contain at any given time? How many cell cycles should it take before all of the cells in most clones should have arrested? Such questions are well studied in mathematics (Athreya \& Ney, 1972), and easily solved by computer simulation. For this particular

211 problem, there are two key results (Figure 4).

212 First, the time after which one can expect clones to have stopped growing (e.g. when all cells 213 will have arrested in, say, $95 \%$ or $99 \%$ of clones) is a steep function of $s$. If $s<0.5$, (i.e. less than

214 a $50 \%$ chance of arrest per cell cycle), then some clones will never stop growing. If $s$ is, say, 2150.53 , all clones will eventually stop growing, but one must wait 51 cell cycles before $99 \%$ of them 216 do so (Fig. 4A). Given typical lengths of postnatal mammalian cell cycles, and the fact that we observe cessation of mouse nevus growth in about 2-3 weeks, we may consider 30 to be a generous estimate for the maximum number of cell cycles by which nevi stop growing. To achieve $99 \%$ clonal arrest by 30 cell cycles, $s$ must be around 0.56 or higher; to achieve arrest in $95 \%$ of clones, $s$ must be greater than 0.52 (Fig. 4A).

From the same simulations one may also calculate predicted distributions of clone sizes. There is a clear reciprocal relationship between mean clone size and the fraction of clones that arrest by 30 cell cycles of time (Fig. 4B). For example, a value of $s$ that enables $95 \%$ of clones to arrest produces a mean clone size of only 18.5 cells. For comparison, we estimate cell numbers per nevus to be in the range of 100-1000 cells (see Methods).

The explanation for the small mean clone sizes produced by simulations can be appreciated by examining the full size distributions. As shown in Fig 4C-D, such distributions are extremely 228 heavy-tailed, with a very large number of very small clones and a small number of very large 229 clones (the histograms in Fig. 4C-D are plotted with logarithmic abscissa to facilitate display of all 230 clone sizes).

231 Qualitatively, this is very different from what we observed for nevi on the backs of p21 mice. 232 Nevi displayed a mean radius of $76.8 \mu \mathrm{m}$ (corresponding to an area of $0.019 \mathrm{~mm}^{2}$, in excellent 233 agreement with the results of (Damsky et al., 2015)) and. when plotted on a logarithmic scale, 234 individual radii displayed a Gaussian-like distribution (Fig. 4E; a Gaussian shape on a logarithmic 235 axis is usually referred to as "log-normal"). Interestingly, nest sizes (quantified by MPM) also 236 seem to be log-normally distributed whether at P21 (Fig. S4A) or P50 (Fig. S4B). So are the nests 237 within human melanocytic nevi, despite the latter being an order of magnitude larger than those 238 in mice (Fig. S4C). It should be noted that using different units to represent simulation results 239 (cell numbers) and empirical data (linear dimension) in Fig. 4 and S4 does not confound 

scales as some power of linear dimension, values associated with log-transformed bins are simply
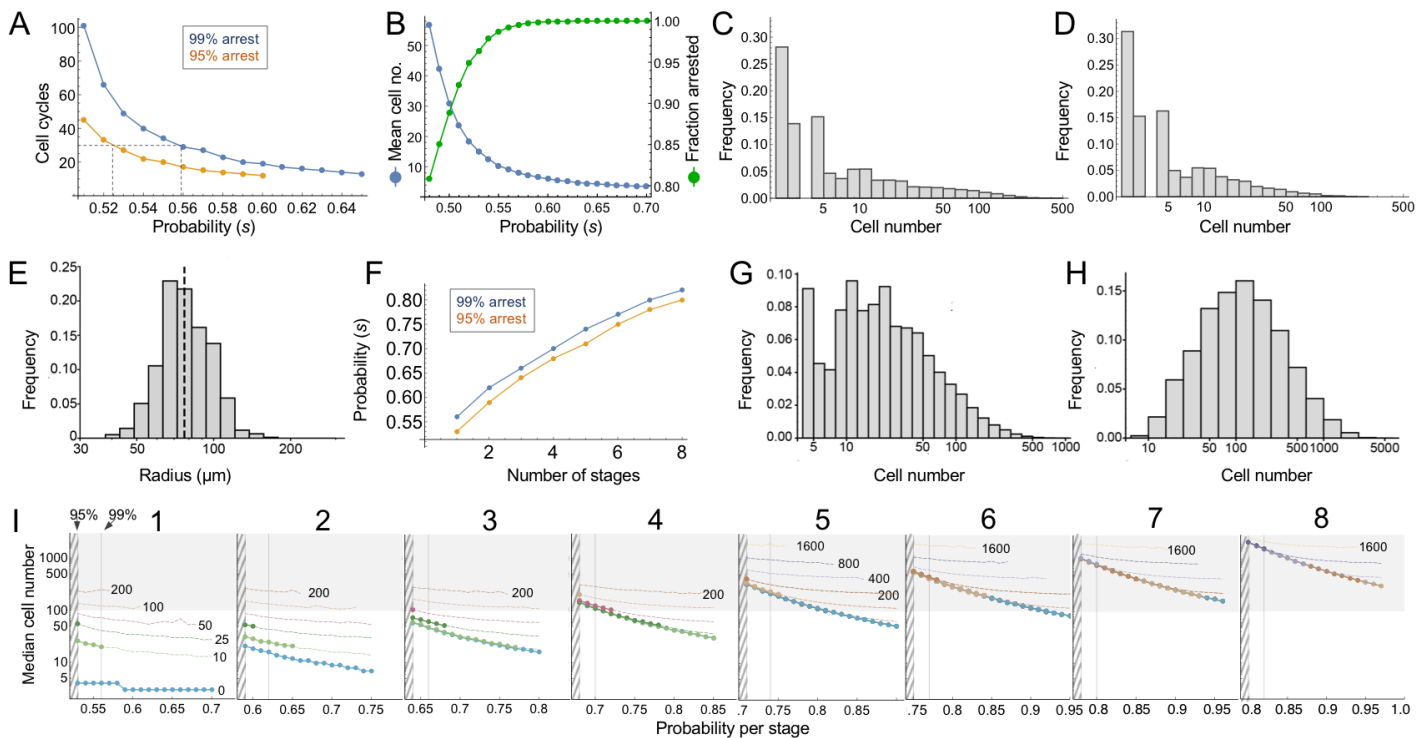

Figure 4. Modeling cell-autonomous clonal arrest as a probabilistic process. A-D. Monte Carlo simulations were carried out in which a single cell replicates and arrests with fixed probability, $s$, per cell cycle. A. Cell cycles required before proliferation stops in $95 \%$ or $99 \%$ of simulations. B. Mean cells at 30 cell cycles, and the fraction of clones that can be expected to have arrested by then. CD. Clone (nevus) size distributions, after 30 cell cycles, assuming $s=0.56$ (C) or 0.53 (D). E. Actual

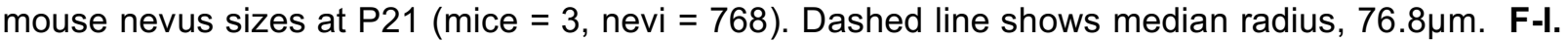
Simulations in which proliferating cells arrest after multiple events (stages). F. The value of $s$ required to ensure arrest within 30 cell cycles, as a function of number of stages. G-H. Clone size distributions for two $(\mathrm{G})$, or three $(\mathrm{H})$ stages, assuming the lowest per-stage transition probability compatible with $99 \%$ arrest by 30 cell cycles (see panel C). I. Median clone size for different numbers of stages (labeled above each graph), transition probabilities per stage (plotted on the abscissa), and thresholds below which clones are excluded from analysis. Each curve represents a different exclusion threshold (between 0 and 200 cells for 1-4 stages, and up to 1600 cells for $5-8$ stages, as labeled). Curves become dashed at the point where the observability threshold exceeds $50 \%$ of the median cell number (values along the dashed segments require most observed nevi to be only barely larger than the limits of observation, which qualitatively disagrees with observations). Within the hatched region, fewer than $95 \%$ of clones arrest by 30 cell cycles. The thin line to right of the hatched region marks the probability at which $99 \%$ of clones arrest by 30 cell cycles. Solid gray demarcates median cell numbers between 100 and 3000 (see text). All results are from a minimum of 20,000 simulations. 
scaled by a constant factor.

243 The above comparison of observed distributions with the results of computer simulation is not 244 entirely fair, however: Simulations track all clones, no matter how small, whereas empirical 245 distributions undoubtedly omit nevi with sizes below some threshold of observability. To correct 246 for this, one can truncate simulated distributions to remove clones smaller than some threshold 247 size. With no a priori way to know what threshold to use, we examined the entire range of 248 plausible truncations (up to the largest clone sizes). As it turns out, the relative shapes of 249 simulated distributions were about the same regardless of where they were truncated. The 250 reason for this behavior can be understood by displaying simulated distributions (with bin sizes of 251 one cell) on a log-log plot, and observing that they fall, over most clone size ranges, on a straight 252 line (see Supplemental Material). This implies an approximately "power law" relationship which, 253 by definition, is scale-free, i.e. has the same relative shape over any range of observations. In 254 fact, for $s$ reasonably close to 0.5 , the approximate probability of observing any clone size can be 255 shown analytically to vary inversely with the 3/2-power of size (for derivation, see Supplemental 256 Material).

257 These data imply that observed nevus size distributions cannot be generated by any cellautonomous, random, time independent, one-step process. But they do not speak to whether a more complicated random process, for example, one with several steps, might suffice. To address this, one can simulate clonal evolution under multi-step models. Again, dynamic predictions can be made. First, to achieve clonal stopping times within 30 cell cycles, the minimum per-step transition probability increases with the number of steps (Fig. 4F). For example,

263 if it takes three random events to arrest growth in $99 \%$ of clones, the average probability of each 264 event needs to be at least 0.66 per cell cycle; with five random events that number is 0.74 .

265 Second, although distributions generated by such models still tend to be heavy-tailed (Fig. $2664 \mathrm{G}$ ), they become less so as the number of steps increases (Fig. 4H), gradually approaching 267 something that looks log-normal. This makes mathematical sense: as per-cell-cycle probabilities 268 approach unity, the system approaches a clock that simply ticks off a fixed number of cell cycles 269 before stopping. A scenario in which all clones stop at roughly the same time, plus or minus some 270 variation, necessarily produces a log-normal distribution, since the logarithm of cell size will be 271 proportional to the number of cell divisions.

272 To determine how many independent steps would be required for a random cell-autonomous 273 process to produce distributions that fit those we observed for nevi, we simulated up to eight 274 random stages, over a variety of transition probabilities (Fig. 4I). We subjected the results to a 
275 range of possible truncations, from 0 to 1600 cells, to mimic any observability cutoffs in the 276 empirical data, and recorded the median clone sizes produced under each of these scenarios.

277 As described below (see Methods), we estimate that the average nevus has about 500-1000

278 cells, but given possible errors in the estimate, we consider here a range of values between 100

279 and 3000 (gray-shaded area in Fig. 4I). Subject to the constraint that enough clones must arrest

280 within 30 cell cycles, and that observation thresholds cannot be so high that the observed median

281 is less than twice the threshold, we find that, to produce nevi of even 200 cells requires 4-5

282 independent events (stages), depending on whether one requires $95 \%$ or $99 \%$ clonal arrest; to 283 reach 500 cells requires 6-7 events. To reach even larger numbers-as would be found in human 284 nevi, or in other mouse models (Chai et al., 2014)—would require even more stages.

\section{Does a collective process arrest nevi?}

286 The above results indicate that, to generate in vivo-like distributions of nevi, a process something like a clock is needed, with cells either counting elapsed divisions (or time) since oncogene activation, or progressing through a sufficiently large sequence of random processes, with tightly controlled probabilities, so that the net outcome is clock-like.

290 Cell-autonomous counting of cell cycles (up to about 12) can occur in early, cleavage-stage embryos (Tadros \& Lipshitz, 2009), but no mechanism has been described to enable growing (as opposed to merely cleaving) cells to track more than a small handful of divisions (or the equivalent amount of time). Erosion of telomeres can mark the passage of large amounts of time in some cells, but this does not seem to occur to any significant degree in nevus melanocytes (Michaloglou et al., 2005)).

In contrast, if growth arrest is not cell-autonomous, but driven by cell-cell communication, then clock-like behavior is easily achieved, without any sort of intrinsic cell memory: Consider a simple communication circuit in which every cell's arrest probability is simply a monotonically increasing 299 function of the number of cells around it that have already arrested (Fig. 5A). This mechanism

300 describes a dynamically well-understood feedback process that normal tissues use to control size 301 (Lander, 2011; Lander et al., 2009). Termed "renewal control” (Buzi et al., 2015), because 302 differentiated cells control the probability that progenitor cells self-renew, the process is often 303 mediated by secreted TGF- $\beta$ superfamily members such as myostatin. activin and GDF11 304 (Gokoffski et al., 2011; Lee et al., 2005). Because it implements the engineering principle of 

are independent of parameters such as cell cycle speed or the starting numbers of cells (Buzi et
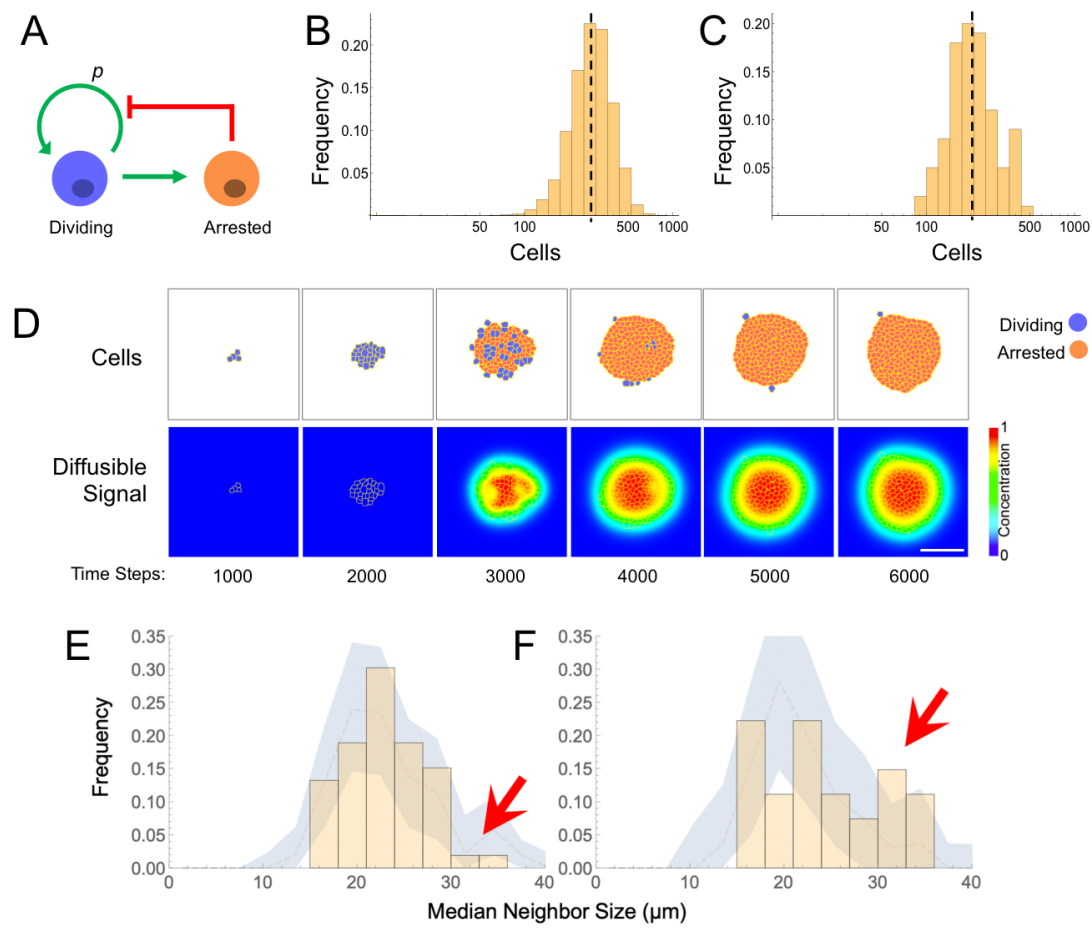

Figure 5. Models and evidence for cooperative, feedback-mediated arrest. A. A generic integral negative feedback scheme. "Renewal probability", $p$, is the probability that offspring of cell division remain dividing (i.e. $1-p$ is the probability that they arrest). B. Clone sizes generated by 9115 stochastic simulations of scheme A, modeled as an ordinary differential equation, where $p$ falls with the number of arrested cells according to a Hill function with half-maximal effect at 50 arrested cells. C-D. Results from a spatial (agent-based) simulation of scheme A, in which the signal from arrested cells spreads by diffusion. Histogram (C) tabulates clone sizes produced by 100 independent simulations (the histograms in both $B$ and $C$ are logarithmically-scaled to show that the data are well fit by log-normal distributions). Panels (D) are from a single simulation, showing locations of growing and arresting cells, and the gradient of the diffusible signal. Bar $=50 \mu \mathrm{m}$. The average cell cycle is equivalent to approximately 382 Monte Carlo time steps. E-F. Using spatial coordinates and areas of 122 nests in seven individual fields at P21, nests were modeled as disks of equivalent area, and mean sizes of neighboring nests falling within successively larger annuli around each target nest were determined. Distributions of mean neighbor sizes up to $45 \mu \mathrm{m}$ away from (E) large (radius $>20 \mu \mathrm{m}$ ) and (F) small (radius < 20 $\mu \mathrm{m}$ ) nests (histograms) are compared with a "null distribution" derived by random permutation (blue fields). Arrows show deviations in neighbor size distribution greater than expected at random, and substantially different for large versus small nests. 
al., 2015; Lander, 2011; Lander et al., 2009).

When growth arrest due to renewal control is simulated as a probabilistic process (Fig. 5B), the observed size distributions of clones is very close to log-normal. This is because renewal control effectively enforces cell cooperation, so that once a small fraction of a clone has arrested, the entire clone stops soon thereafter. The resulting narrow distribution of stopping times produces size distributions that are approximately log-normal, i.e. that emulate a clock.

This behavior is a generic outcome of feedback control, and does not depend strongly on the details of how feedback is implemented. Similar distributions are obtained whether we model nevi as progressing reversibly or irreversibly through more than one proliferative stage, or use agent-based simulations in which renewal is controlled by the concentration of a secreted molecule that accumulates according to the laws of diffusion and local uptake (Fig. 5C-D). The point of these simulations is not to argue in favor of a specific feedback mechanism, but rather to show that, where cell-autonomous mechanisms of arrest struggle to fit nevus dynamics, almost any sort of (collective) feedback does so easily.

Although nevus size distributions alone cannot shed light on the molecular details of how feedback might be implemented in nevi, it is interesting that those cells that we identify as nevus melanocytes (Fig. 2) express multiple genes encoding ligands with known or suspected growth inhibitory activities, together with the receptors for those ligands. These include TGF $\beta$ superfamily members Gdf11, Gdf15, Tgfb1, Tgfb2, and Tgfb3, as well as other genes associated with growth

326 inhibition, such as Angpt/2, Angpt/4, II6, Sema3a, Sema3b, and Sema3f (Attisano \& Wrana, 1996;

327 Neufeld et al., 2016; Santulli, 2014).

The evaluation of such candidates (as well as other genes expressed at too low a level to be reliably detected by single cell RNA sequencing) will no doubt require further study. In the 330 meantime, we reasoned that any feedback mechanism based on secreted, diffusible factors 331 should induce spatial correlations among clones. In particular, when clones (or subclones) get 332 close enough to each other, they should inhibit each other's growth, leading to a smaller final size.

333 The distance over which such effects could occur should reflect the spatial decay length of 334 diffusible molecules in the skin, which is thought to be on the order of no more than a few hundred 335 microns (Chen et al., 2015). Although our data on macroscopic nevi (Fig. 1D), which had been 336 collected in a manner that included spatial coordinates, did not contain enough examples of nevus

337 spacings in this range to test this hypothesis, our data on the nests within individual nevi did, as 338 the median spacing between nests at postnatal day 21 was approximately 79 microns. 
To assess whether nests were significantly smaller when located near other nests (especially

340 large ones), we extracted the coordinates and nest areas from 7 separate fields at P21 341 (representing 122 individual nests) and, modeling each nest as a disk of equivalent area, 342 calculated the mean sizes of neighboring nests falling within successively larger annuli around 343 each target nest. We compared the distributions of mean neighbor sizes near the 52 smallest 344 nests (radius $<20 \mu \mathrm{m}$ ) with the equivalent distributions around the 70 largest nests.

345 As shown in Figure 5E-F, within annuli extending $45 \mu \mathrm{m}$ away from the perimeters of target nests, we saw fewer examples of large neighbors (radius $>30 \mu \mathrm{m}$ ) around large nests (panel E)

347 than around small ones (panel F). To determine whether the difference was statistically 348 significant, we used a permutation test in which we randomly swapped nest areas (but not 349 locations) within each field 5000 times, and recalculated the distributions. This allowed us to plot 350 the envelope enclosing the $5^{\text {th }}$ and $95^{\text {th }}$ percentiles for permuted data, onto which we overlaid the 351 observed data. Unlike the observed data, the envelopes of the permuted data (blue zones in Fig. $3525 \mathrm{E}-\mathrm{F}$ ) look similar whether target nests are large or small. Moreover, the observed data extended 353 outside of the envelopes only for median neighbor sizes $>30 \mu \mathrm{m}$, with the data for small target 354 nevi extending well above the relevant envelope and the data for large target nevi lying at to the bottom of the envelope (Fig. 5E-F, arrows). These results argue that proximity is associated with a small, but significant decrease in nest size, supporting the view that nests inhibit each other's growth. Interestingly, when we repeated the same analysis using annulus sizes of $150 \mu \mathrm{m}$, differences in the sizes of neighbors of small and large nests were not seen, consistent with the view that whatever is promoting coordination among nests has a spatial range of $<150 \mu \mathrm{m}$.

\section{DISCUSSION}

361 Studies in man, mouse and fish establish that most melanocytic nevi form by mutational activation 362 of BRAF, which triggers proliferation followed by growth arrest (Damsky \& Bosenberg, 2017; 363 Dankort et al., 2009; Dhomen et al., 2009; Kaufman et al., 2016; Michaloglou et al., 2005; Patton 364 et al., 2005; Shain \& Bastian, 2016). Nevus growth is often considered a paradigmatic example 365 of oncogene-induced senescence (OIS), but here we question two of the major tenets of the OIS 366 hypothesis: that nevus melanocytes are actually senescent; and that growth arrest is a direct 367 effect of oncogene action on the individual cell.

368 To assess whether nevi are senescent, we used single cell RNA sequencing in a mouse 369 model of Braf-driven nevus formation, comparing gene expression of nevus melanocytes with that 370 of other cell types. Across a wide variety of gene expression signatures, especially those 371 developed to distinguish senescence from other growth-arrested cell states, we failed to find any 
372 evidence in support of the OIS hypothesis. By gene expression criteria, nevus melanocytes were

373 less senescent than many other normal skin cells, including non-nevus melanocytes (Fig. 3, S3).

374 These results support earlier work that also questioned, based on immunohistochemical staining

375 of human nevi for markers including lysosomal $\beta$-galactosidase, Ki67, p16 ${ }^{\text {INK4a }}(C D K N 2 A), \gamma-H 2 A X$

376 and p53, whether nevus melanocytes should be considered senescent (Tran et al., 2012). In

377 agreement with other studies, we do find that Cdkn2A is highly expressed in nevus cells; it is in

378 fact the only "classical" senescence marker that clearly distinguishes nevus melanocytes from

379 other melanocytes (Fig. 3A). Yet, as others have shown, Cdkn2A is neither necessary nor

380 sufficient for oncogene-mediated melanocyte growth arrest (Haferkamp et al., 2009; Zeng et al.,

381 2018). Thus, to the extent that nevus melanocytes do execute even part of a common senescence

382 program, there is little to support the view that this why they stop proliferating.

383 As for the question of exactly how Braf-induced nevus growth arrest occurs, Figure 6 presents

384 a continuum of models: In model A, oncogene action elicits a cell-autonomous stress response

385 which, after some time lag, triggers senescence that shuts proliferation down. This is the form in

386 which the OIS hypothesis is most frequently presented.

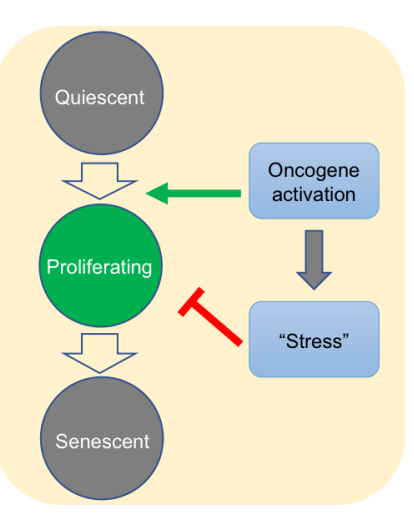

A. Oncogene-Induced Senescence (OIS)

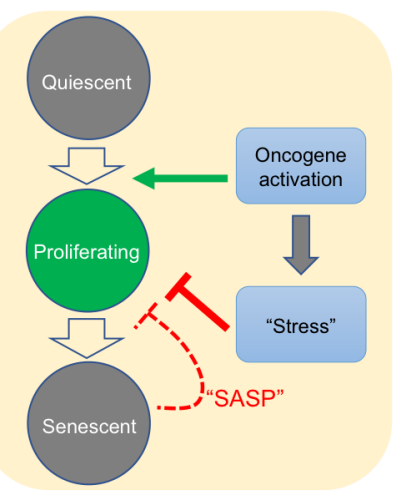

B. OIS with paracrine contributions

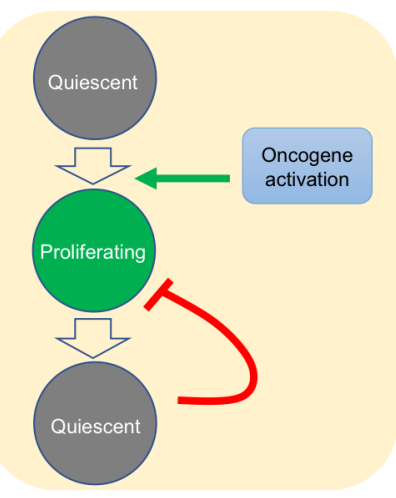

C. Feedback control of renewal

Figure 6. Possible mechanisms of growth arrest. Three different models of nevus growth arrest are presented, varying from classical OIS $(A)$ to feedback control of proliferative cell renewal (C). The model in the middle panel $(B)$ illustrates a hypothetical hybrid situation, in which paracrine effects of senescence-associated secreted proteins (SASP) act as inhibitors of melanocyte self-renewal. Although model $\mathrm{B}$ can mimic some of the dynamic behaviors of model $\mathrm{C}$, in the absence of convincing evidence that nevus melanocytes actually are senescent, we favor model C. 
In model C, growth-arrest is not a direct effect of oncogene action, but rather a consequence of growth itself. This type of feedback is commonly used by adult tissues to maintain constant size, and also enables developing tissues to produce precise numbers of differentiated cells

390 (Kunche et al., 2016; Lander, 2011; Lander et al., 2009). Because of the collective nature of this mechanism-cells that have stopped dividing tell other cells in their vicinity to do likewise-it naturally produces semi-synchronous arrest of spatially-coherent cell clones, and the distinctive log-normal clone size distribution that comes along with that. In contrast, a purely cellautonomous mechanism (panel A) has great difficulty producing such distributions (Fig. 4), either necessitating the operation of some kind of multi-cell-cycle clock, or requiring cells to complete a long sequence of independent probabilistic events prior to arresting (Fig. 4).

One can, of course, build a model in between these two extremes (model B), in which oncogenes induce growth arrest directly, but paracrine signals (i.e. SASP factors) help maintain

399 it. If the paracrine role is important enough, this mechanism might also produce clone size 400 distributions that are approximately log-normal, so we cannot categorically rule this model out. 401 However, our gene expression data do not support any versions of it that have been explicitly 402 proposed for nevi. So far, several groups (working predominantly from in vitro observations) have 403 claimed a critical role for SASP factors in melanocyte OIS: Wajapeyee et al. (Wajapeyee et al., 404 2008) argued that IGFBP7 plays a necessary role in the establishment of BRAF-V600E-induced 405 melanocyte senescence (a conclusion disputed by some (Scurr et al., 2010)); Feuerer et al., 406 (Feuerer et al., 2019) proposed that MIA (melanoma inhibitory activity) secreted by senescent 407 melanocytes is required to maintain senescence; and Damsky and Bosenberg have proposed 408 that IL1, IL6, IL8 (encoded in mouse by Cxcl15), and type 1 interferons produced by nevus cells 409 play a role in their arrest (Damsky \& Bosenberg, 2017).

410 Our in vivo data do not support any of these hypotheses. For example, we observed that the 411 vast majority of Igfbp7 transcripts are produced by fibroblasts and endothelial cells and that, 412 among melanocytes, nevus melanocytes express lower levels of lgfbp7 than non-nevus 413 melanocytes. We did not detect any Mia transcripts in nevus melanocytes, although it was 414 expressed at detectable levels in non-nevus melanocytes and various other skin cells. Likewise, 415 of I/1 family members, only I/1a transcripts were detected in nevus melanocytes and they were at 416 levels lower than in many other skin cell types. I/6 was also only weakly expressed in nevus 417 melanocytes, especially when compared with other cells. Transcripts for type 1 interferons were 418 not detected in any melanocytic cells, and $C x c / 15$ transcripts were not detected in any skin cells 419 at all. 
Of course, the accuracy of single cell RNA sequencing can be limited for weakly expressed genes, so we cannot completely eliminate the possibility that these factors play some role in nevus

422 growth arrest. But given these results, and the evidence that nevus melanocytes are not 423 senescent, we strongly favor the renewal-feedback model (model C). Adopting this model also 424 makes it easier to accommodate long-standing evidence that nevus growth arrest is not 425 permanent (Shain \& Bastian, 2016). For example, it is known that nevi may exhibit a low level of 426 mitoses (Glatz et al., 2010); that they can grow in response to stimuli such as UV light (Rudolph 427 et al., 1998) or immunosuppression (Shain \& Bastian, 2016) and, perhaps most tellingly, they can 428 re-grow after incomplete surgical resection-stopping again when they reach a typical nevus size 429 (Vilain et al., 2016). The latter result is inherently problematic for any non-feedback model, but is 430 precisely what renewal feedback predicts (Lander, 2011; Lander et al., 2009).

431 Because feedback control of renewal implements a generic strategy (integral negative feedback (Lander, 2011)), it places no constraints on the molecular details of feedback, short of 433 the fact that whatever is mediating it needs to rise with the number of cells already arrested. One possibility is that nevi are responding to some of the same signals that are used in melanocyte homeostasis. For instance, during anagen phase of the hair cycle, melanocyte stem cells produce progeny that migrate out of the hair follicle bulge as they differentiate, leaving functional stem cells behind for future cycles. A variety of experimental and pathological circumstances that allow small numbers of melanocytes to differentiate within the bulge cause differentiation and loss of the entire stem cell pool (with concomitant hair graying (Nishimura et al., 2005)). This sort of

440 behavior-where differentiated cells drive the differentiation of their progenitors-is exactly the 441 sort of behavior that drives feedback models of renewal (Buzi et al., 2015; Lander, 2011; Lander 442 et al., 2009).

443 Nevi are but one of many types of benign, clonal, proliferative lesions that arise due to the 444 activation of oncogenes, but rarely if ever progress to malignancy (Adashek et al., 2020). 445 Notwithstanding the disruptive influence that oncogenes can have on cell physiology, the 446 existence of such lesions suggest that homeostatic mechanisms persist and function at many 447 stages along the road to cancer. New avenues for cancer prevention and treatment are likely to 448 follow from the detailed elucidation of such mechanisms.

450 Experimental Design

451 Mouse treatment for nevus development

$452 \quad B r a f^{V 600 E}$, Tyr:CreER (C56BL/6) mice were genotyped by PCR as previously described 453 (Bosenberg et al., 2006; Dankort et al., 2007). The primers used in this study are: Braf forward 
5'-TGAGTATTTTTGTGGCAACTGC -3', Braf reverse 5'-CTCTGCTGGGAAAGCGCC -3', Cre

455 forward 5'- GGTGTCCAATTTACTGACCGTACA-3' and Cre reverse 5'-

456 CGGATCCGCCGCATAACCAGTG -3'. Topical administration of 4-hydroxytamoxifen (4-OHT;

$45725 \mathrm{mg} / \mathrm{mL}$ or $75 \mathrm{mg} / \mathrm{mL}$ in DMSO; $98 \%$ Z-isomer, Sigma-Aldrich) was administered to pups on their

458 back and/or paws at ages P2, P3, and P4. Images of nevi on back and paw skin were taken with

459 a digital camera at the indicated ages. Nevi from the underside of the skin were imaged using a

460 dissection microscope. All mouse procedures were approved by UCl's IACUC.

\section{Live imaging of the skin by multi-photon microscopy}

Mice were sedated, shaved, and depilated with wax strips at the indicated ages (during a telogen phase) and the dorsal skin was imaged to capture the intrinsic fluorescent signal from keratin, melanin, as well as the second-harmonic-generation signal from collagen, using the LSM 510 NLO Zeiss system. Excitation was achieved with a femtosecond Titanium: Sapphire (Chameleon-Ultra, Coherent) laser at $900 \mathrm{~nm}$. Emission was detected at 390-465 nm for second harmonic generation (blue) and 500-550 nm (green) and 565-650 (red) for fluorescence.

\section{In vivo labeling with BrdU}

BrdU was prepared in sterile PBS at $10 \mathrm{mg} / \mathrm{mL}$ and injected intraperitoneally into mice that were 20 days old at $100 \mathrm{mg} / \mathrm{kg}$ of body weight. 24 hours later the mouse was shaved, depilated with wax strips and the skin was removed and fixed in $10 \%$ formalin for 16 hours.

\section{Immunofluorescence}

Formalin fixed paraffin embedded skins were sectioned $8 \mu \mathrm{m}$ thick, deparaffinized with Xylene, and dehydrated in a series of increasing concentration of ethanol washes. Antigen retrieval was performed with $10 \mathrm{mM}$ citric acid buffer at $\mathrm{pH} 6.0$ for $10 \mathrm{~min}$ in a steamer. Samples were washed with PBS, incubated with TrueBlack for 30 seconds to reduce autofluorescence, and washed again with PBS. All antibodies were diluted at a 1:500 and incubated overnight at $4^{\circ} \mathrm{C}$. Samples

481 were washed and incubated with the appropriate secondary antibody. Melanocytes were

482 identified with a Pmel antibody (EP4863(2); ab137078, Abcam). Cells that incorporated BrdU 483 were visualized with a BrdU antibody (ab6326, Abcam).

485 Cell Isolation for Single Cell RNA Sequencing

$486 \quad B r a f^{W T}$, Tyr::CreER or Braf ${ }^{V 600 E}$, Tyr::CreER mice were euthanized at either P30 ( $n=2$ of each 487 genotype) or P50 ( $\mathrm{n}=3$ of each genotype), shaved, and depilated. A $2 \times 3 \mathrm{~cm}$ section of the dorsal 
skin was removed, and the fat scraped off from the underside. The piece was then diced into smaller pieces and suspended in dissociation buffer (RPMI, liberase $0.25 \mathrm{mg} / \mathrm{mL}$, Hepes $23.2 \mathrm{mM}$,

490 Sodium Pyruvate 2.32mM, Collagenase:Dispase $1 \mathrm{mg} / \mathrm{mL}$ ) for 50 minutes at $37^{\circ} \mathrm{C}$ with gentle

491 agitation. After incubation, DNasel (232U) was added for 10 minutes and then inactivated with

492 fetal bovine serum and EDTA $(1 \mathrm{mM})$. The tissue suspension was further dissociated 493 mechanically with the GentleMACS using the setting m_imptumor_04.01, which runs for 37 494 seconds at various speeds. Single cell suspensions were filtered twice through a $70 \mu \mathrm{m}$ strainer 495 and dead cells removed by centrifugation at $300 \times g$ for $15 \mathrm{~min}$. The live cells were washed with $496 \quad 0.04 \%$ UltraPure BSA:PBS buffer, gently re-suspended in the same buffer, and counted using 497 trypan blue.

\section{Library Preparation for Single Cell RNA Sequencing and Analysis}

500 Libraries were prepared using the Chromium Single Cell 3' v2 protocol (10X Genomics).

501 Briefly, individual cells and gel beads were encapsulated in oil droplets where cells were lysed

502 and mRNA was reverse transcribed to 10X barcoded cDNA. Adapters were ligated to the cDNA 503 followed by the addition of the sample index. Prepared libraries were sequenced using paired 504 end 100 cycles chemistry for the Illumina HiSeq 4000. FASTQ files were generated from 505 Illumina's binary base call raw output with Cell Ranger's (v2.1.0) 'cellranger mkfastq command 506 and the count matrix for each sample was produced with 'cellranger count'. All ten samples (4 507 samples from P30 [two control (wild type) and two mutant] and 6 samples from P50 [three control 508 and three mutant]) were aggregated together with the 'cellranger aggr' command to produce one 509 count matrix that includes all samples. Data analysis was performed with Scanpy [v1.3.6] (Wolf 510 et al., 2018). Cells with fewer than 200 detected genes, and genes detected in less than three 511 cells, were discarded. We calculated the percent mitochondrial gene expression and kept cells 512 with less than $13 \%$ mitochondrial gene expression, and cells with fewer than 4000 genes/cell 513 (35,141 cells). Each cell was normalized to total counts over all genes. In the final preprocessing 514 step, we regressed out cell-cell variation driven by mitochondrial gene expression and the number 515 of detected UMI. To identify clusters, we first performed principal component analysis on log516 transformed data, using highly variable genes, Louvain clustering (Levine et al., 2015), and 517 visualization with t-distributed stochastic neighbor embedding (tSNE).

\section{Quantification of nevus and nest size and cell content}

520 To quantify the sizes of nevi in mice, dorsal skin was excised and the underside visualized 521 using a dissecting microscope. Nevi were traced, and area calculated using ImageJ. Nest sizes 
522 were quantified in live mice by MPM. Sizes of human nests were measured from histological 523 samples $(n=5)$ obtained from the UCI Department of Dermatology. Samples were stained with

524 hematoxylin and eosin and imaged with a microscope. A dermatologist manually identified the 525 nests on each slide, and nest area was quantified using ImageJ. Human studies were performed 526 under IRB protocol HS\# 2019-5054.

527 Estimates of cell numbers for mouse nevi were obtained in two different ways: First, we used 528 estimates from (Chai et al., 2014) for melanocytic nuclei per square area of mouse nevus, together 529 with our observed median nevus radius of $76.8 \mu \mathrm{m}$; this approach led to an estimate of 897 530 cells/nevus. As the data of (Chai et al., 2014) come from a different genetic model, we also 531 estimated cell number as follows: Using $8 \mu \mathrm{m}$ sections of back skin from Albino Braf ${ }^{\mathrm{V} 600 \mathrm{E}}$ mice, $^{\mathrm{V}}$ 532 we used fluorescence microscopy to measure the sizes of 194 Pmel-stained melanocytes within 533 the nests of nevi, obtaining an average cell diameter of $5.68 \mu \mathrm{m}$, and counted approximately 14.4 534 cells per $10^{4} \mu^{3}$ of nest. In pigmented animals, we measured by MPM an average nest cross 535 sectional area of $1385{\mu \mathrm{m}^{2}}^{2}$, an average nest volume of $38792 \mu^{3}$, and an average number of 536 nests per nevi of approximately 12, yielding an estimate of 672 cells/nevus. Given uncertainties in these measures, analyses in the manuscript take into account the possibility of an average that falls anywhere between 100 and 1000 cells.

\section{Simulations and Agent-Based Modeling}

541 Stochastic, non-spatial simulations of renewal control were obtained by Monte Carlo simulation, in which cells duplicated every cell cycle, and then chose randomly whether to differentiate or continue dividing according to a probability modified by feedback from non-dividing cells. A Hill function, with Hill coefficient =1, was used to represent the feedback.

To model feedback in a spatial context, we used CompuCell3D, an open-source platform for Cellular Potts modeling (Swat et al., 2012). In CPM, every generalized object or "cell" is associated with a list of attributes such as cell type, surface area, volume, etc. These enter into the calculation of an effective energy, which can be summarized as the sum of the contact energy between neighboring cells and the effective energy due to volume constraints.

550 Simulations were initialized by seeding a single cell, with a size of 25 pixel $^{2}$, in the center of a $300 \times 300$ pixel lattice, which grew and divided according to rules and parameters summarized

552 in Data S2. To add variability to cell growth, cells randomly chose one of three different growth 553 rates after every cell division. To add variability to cell division times, cells randomly chose a target 554 area, between 72 and 80 pixel $^{2}$, at which to divide. Growth rates were chosen to be sufficiently 555 slow that the mean time between cell divisions came out to approximately 382 time steps. At 
division, each cell was divided in half by a randomly-oriented division plane.

Upon division, a cell either remained dividing or became permanently arrested. All cells had a minimum $1 \%$ probability of arrest per cell division. Once an arrested cell was generated, it began continuous secretion of a signaling molecule that diffuses and promotes the transition from dividing to non-dividing (Kunche et al., 2016). Diffusion and decay of the feedback factor was modeled deterministically, with parameters chosen to produce a steady state decay length of 15 pixels. The concentration of this factor at the center of mass of each cell then augmented the arrest probability of that cell by an amount determined by a Hill function (see Data S2).

\section{Statistical Analysis}

Statistical analyses for single cell RNA sequencing were performed using Scanpy. Other statistical testing was done using Mathematica. For the spatial analysis in Figure 5E-F, nest areas in each field were randomly swapped, with positions held constant, 5000 times, and the distributions of neighboring nest locations and sizes re-calculated each time. This allowed us to generate an envelope enclosing the $5^{\text {th }}$ and $95^{\text {th }}$ percentiles for the permuted data, at each target nest size, and compare the observed data with the bounds of that envelope.

\section{References}

Acosta, J. C., Banito, A., Wuestefeld, T., Georgilis, A., Janich, P., Morton, J. P., Athineos, D., Kang, T. W., Lasitschka, F., Andrulis, M., Pascual, G., Morris, K. J., Khan, S., Jin, H., Dharmalingam, G., Snijders, A. P., Carroll, T., Capper, D., Pritchard, C., Inman, G. J., Longerich, T., Sansom, O. J., Benitah, S. A., Zender, L., \& Gil, J. (2013). A complex secretory program orchestrated by the inflammasome controls paracrine senescence. Nat Cell Biol, 15(8), 978-990. https://doi.org/10.1038/ncb2784

Adashek, J. J., Kato, S., Lippman, S. M., \& Kurzrock, R. (2020). The paradox of cancer genes in non-malignant conditions: implications for precision medicine. Genome Med, 12(1), 16. https://doi.org/10.1186/s13073-020-0714-y

Athreya, K. B., \& Ney, P. E. (1972). Branching Processes (2nd ed.). Dover.

Attisano, L., \& Wrana, J. L. (1996). Signal transduction by members of the transforming growth factor-beta superfamily. Cytokine Growth Factor Rev, 7(4), 327-339. https://doi.org/10.1016/s1359-6101(96)00042-1

Beausejour, C. M., Krtolica, A., Galimi, F., Narita, M., Lowe, S. W., Yaswen, P., \& Campisi, J. (2003). Reversal of human cellular senescence: roles of the p53 and p16 pathways. EMBO J, 22(16), 4212-4222. https://doi.org/10.1093/emboj/cdg417

Bennett, D. C. (2003). Human melanocyte senescence and melanoma susceptibility genes. Oncogene, 22(20), 3063-3069. https://doi.org/10.1038/sj.onc.1206446

Bosenberg, M., Muthusamy, V., Curley, D. P., Wang, Z., Hobbs, C., Nelson, B., Nogueira, C., Horner, J. W., 2nd, Depinho, R., \& Chin, L. (2006). Characterization of melanocytespecific inducible Cre recombinase transgenic mice. Genesis, 44(5), 262-267. https://doi.org/10.1002/dvg.20205 
596

597

598

599

600

601

602

603

604

605

606

607

608

609

610

611

612

613

614

615

616

617

618

619

620

621

622

623

624

625

626

627

628

629

630

631

632

633

634

635

636

637

638

639

640

641

642

643

644

645
Buzi, G., Lander, A. D., \& Khammash, M. (2015). Cell lineage branching as a strategy for proliferative control. BMC Biol, 13, 13. https://doi.org/10.1186/s12915-015-0122-8

Campisi, J., \& d'Adda di Fagagna, F. (2007). Cellular senescence: when bad things happen to good cells. Nat Rev Mol Cell Biol, 8(9), 729-740. https://doi.org/10.1038/nrm2233

Chai, E., Ferguson, B., Prow, T., Soyer, P., \& Walker, G. (2014). Three-dimensional modelling for estimation of nevus count and probability of nevus-melanoma progression in a murine model. Pigment Cell Melanoma Res, 27(2), 317-319.

https://doi.org/10.1111/pcmr.12195

Chatsirisupachai, K., Palmer, D., Ferreira, S., \& de Magalhaes, J. P. (2019). A human tissuespecific transcriptomic analysis reveals a complex relationship between aging, cancer, and cellular senescence. Aging Cell, 18(6), e13041. https://doi.org/10.1111/acel.13041

Chen, C. C., Wang, L., Plikus, M. V., Jiang, T. X., Murray, P. J., Ramos, R., Guerrero-Juarez, C. F., Hughes, M. W., Lee, O. K., Shi, S., Widelitz, R. B., Lander, A. D., \& Chuong, C. M. (2015). Organ-level quorum sensing directs regeneration in hair stem cell populations. Cell, 161(2), 277-290. https://doi.org/10.1016/j.cell.2015.02.016

Collado, M., \& Serrano, M. (2006). The power and the promise of oncogene-induced senescence markers. Nat Rev Cancer, 6(6), 472-476. https://doi.org/10.1038/nrc1884

Damsky, W. E., \& Bosenberg, M. (2017). Melanocytic nevi and melanoma: unraveling a complex relationship. Oncogene, 36(42), 5771-5792. https://doi.org/10.1038/onc.2017.189

Damsky, W. E., Micevic, G., Meeth, K., Muthusamy, V., Curley, D. P., Santhanakrishnan, M., Erdelyi, I., Platt, J. T., Huang, L., Theodosakis, N., Zaidi, M. R., Tighe, S., Davies, M. A., Dankort, D., McMahon, M., Merlino, G., Bardeesy, N., \& Bosenberg, M. (2015). mTORC1 activation blocks BrafV600E-induced growth arrest but is insufficient for melanoma formation. Cancer Cell, 27(1), 41-56. https://doi.org/10.1016/j.ccell.2014.11.014

Dankort, D., Curley, D. P., Cartlidge, R. A., Nelson, B., Karnezis, A. N., Damsky, W. E., Jr., You, M. J., DePinho, R. A., McMahon, M., \& Bosenberg, M. (2009). Braf(V600E) cooperates with Pten loss to induce metastatic melanoma. Nat Genet, 41(5), 544-552. https://doi.org/10.1038/ng.356

Dankort, D., Filenova, E., Collado, M., Serrano, M., Jones, K., \& McMahon, M. (2007). A new mouse model to explore the initiation, progression, and therapy of BRAFV600E-induced lung tumors. Genes Dev, 21(4), 379-384. https://doi.org/10.1101/gad.1516407

Davies, H., Bignell, G. R., Cox, C., Stephens, P., Edkins, S., Clegg, S., Teague, J., Woffendin, H., Garnett, M. J., Bottomley, W., Davis, N., Dicks, E., Ewing, R., Floyd, Y., Gray, K., Hall, S., Hawes, R., Hughes, J., Kosmidou, V., Menzies, A., Mould, C., Parker, A., Stevens, C., Watt, S., Hooper, S., Wilson, R., Jayatilake, H., Gusterson, B. A., Cooper, C., Shipley, J., Hargrave, D., Pritchard-Jones, K., Maitland, N., Chenevix-Trench, G., Riggins, G. J., Bigner, D. D., Palmieri, G., Cossu, A., Flanagan, A., Nicholson, A., Ho, J. W., Leung, S. Y., Yuen, S. T., Weber, B. L., Seigler, H. F., Darrow, T. L., Paterson, H., Marais, R., Marshall, C. J., Wooster, R., Stratton, M. R., \& Futreal, P. A. (2002). Mutations of the BRAF gene in human cancer. Nature, 417(6892), 949-954. https://doi.org/10.1038/nature00766

Dhomen, N., Reis-Filho, J. S., da Rocha Dias, S., Hayward, R., Savage, K., Delmas, V., Larue, L., Pritchard, C., \& Marais, R. (2009). Oncogenic Braf induces melanocyte senescence and melanoma in mice. Cancer Cell, 15(4), 294-303. https://doi.org/10.1016/j.ccr.2009.02.022

Elzi, D. J., Song, M., Hakala, K., Weintraub, S. T., \& Shiio, Y. (2012). Wnt antagonist SFRP1 functions as a secreted mediator of senescence. Mol Cell Biol, 32(21), 4388-4399. https://doi.org/10.1128/MCB.06023-11 
646

647

648

649

650

651

652

653

654

655

656

657

658

659

660

661

662

663

664

665

666

667

668

669

670

671

672

673

674

675

676

677

678

679

680

681

682

683

684

685

686

687

688

689

690

691

692

693

694

695

696

Feuerer, L., Lamm, S., Henz, I., Kappelmann-Fenzl, M., Haferkamp, S., Meierjohann, S., Hellerbrand, C., Kuphal, S., \& Bosserhoff, A. K. (2019). Role of melanoma inhibitory activity in melanocyte senescence. Pigment Cell \& Melanoma Research, 32(6), 777-791. https://doi.org/10.1111/pcmr.12801

Glatz, K., Hartmann, C., Antic, M., \& Kutzner, H. (2010). Frequent mitotic activity in banal melanocytic nevi uncovered by immunohistochemical analysis. Am J Dermatopathol, 32(7), 643-649. https://doi.org/10.1097/DAD.0b013e3181d7ce6f

Gokoffski, K. K., Wu, H. H., Beites, C. L., Kim, J., Kim, E. J., Matzuk, M. M., Johnson, J. E., Lander, A. D., \& Calof, A. L. (2011). Activin and GDF11 collaborate in feedback control of neuroepithelial stem cell proliferation and fate. Development, 138(19), 4131-4142. https://doi.org/10.1242/dev.065870

Gorgoulis, V., Adams, P. D., Alimonti, A., Bennett, D. C., Bischof, O., Bishop, C., Campisi, J., Collado, M., Evangelou, K., Ferbeyre, G., Gil, J., Hara, E., Krizhanovsky, V., Jurk, D., Maier, A. B., Narita, M., Niedernhofer, L., Passos, J. F., Robbins, P. D., Schmitt, C. A., Sedivy, J., Vougas, K., von Zglinicki, T., Zhou, D., Serrano, M., \& Demaria, M. (2019). Cellular Senescence: Defining a Path Forward. Cell, 179(4), 813-827. https://doi.org/10.1016/j.cell.2019.10.005

Haferkamp, S., Scurr, L. L., Becker, T. M., Frausto, M., Kefford, R. F., \& Rizos, H. (2009). Oncogene-induced senescence does not require the p16(INK4a) or p14ARF melanoma tumor suppressors. J Invest Dermatol, 129(8), 1983-1991. https://doi.org/10.1038/jid.2009.5

Hernandez-Segura, A., de Jong, T. V., Melov, S., Guryev, V., Campisi, J., \& Demaria, M. (2017). Unmasking Transcriptional Heterogeneity in Senescent Cells. Curr Biol, 27(17), 2652-2660 e2654. https://doi.org/10.1016/j.cub.2017.07.033

Huang, J. M., Chikeka, I., \& Hornyak, T. J. (2017). Melanocytic Nevi and the Genetic and Epigenetic Control of Oncogene-Induced Senescence. Dermatol Clin, 35(1), 85-93. https://doi.org/10.1016/j.det.2016.08.001

Ito, Y., Hoare, M., \& Narita, M. (2017). Spatial and Temporal Control of Senescence. Trends Cell Biol, 27(11), 820-832. https://doi.org/10.1016/j.tcb.2017.07.004

Joost, S., Annusver, K., Jacob, T., Sun, X., Dalessandri, T., Sivan, U., Sequeira, I., Sandberg, R., \& Kasper, M. (2020). The Molecular Anatomy of Mouse Skin during Hair Growth and Rest. Cell Stem Cell, 26(3), 441-457 e447. https://doi.org/10.1016/j.stem.2020.01.012

Joshi, S. S., Tandukar, B., Pan, L., Huang, J. M., Livak, F., Smith, B. J., Hodges, T., Mahurkar, A. A., \& Hornyak, T. J. (2019). CD34 defines melanocyte stem cell subpopulations with distinct regenerative properties. PLoS Genet, 15(4), e1008034. https://doi.org/10.1371/journal.pgen.1008034

Kaplon, J., Homig-Holzel, C., Gao, L., Meissl, K., Verdegaal, E. M., van der Burg, S. H., van Doorn, R., \& Peeper, D. S. (2014). Near-genomewide RNAi screening for regulators of BRAF(V600E) -induced senescence identifies RASEF, a gene epigenetically silenced in melanoma. Pigment Cell Melanoma Res, 27(4), 640-652.

https://doi.org/10.1111/pcmr.12248

Kaufman, C. K., Mosimann, C., Fan, Z. P., Yang, S., Thomas, A. J., Ablain, J., Tan, J. L., Fogley, R. D., van Rooijen, E., Hagedorn, E. J., Ciarlo, C., White, R. M., Matos, D. A., Puller, A. C., Santoriello, C., Liao, E. C., Young, R. A., \& Zon, L. I. (2016). A zebrafish melanoma model reveals emergence of neural crest identity during melanoma initiation. Science, 351(6272), aad2197. https://doi.org/351/6272/aad2197 [pii]

10.1126/science.aad2197

Kuilman, T., Michaloglou, C., Mooi, W. J., \& Peeper, D. S. (2010). The essence of senescence. Genes Dev, 24(22), 2463-2479. https://doi.org/10.1101/gad.1971610

Kuilman, T., Michaloglou, C., Vredeveld, L. C., Douma, S., van Doorn, R., Desmet, C. J., Aarden, L. A., Mooi, W. J., \& Peeper, D. S. (2008). Oncogene-induced senescence 
relayed by an interleukin-dependent inflammatory network. Cell, 133(6), 1019-1031. https://doi.org/10.1016/j.cell.2008.03.039

Kunche, S., Yan, H., Calof, A. L., Lowengrub, J. S., \& Lander, A. D. (2016). Feedback, Lineages and Self-Organizing Morphogenesis. PLoS Comput Biol, 12(3), e1004814. https://doi.org/10.1371/journal.pcbi.1004814

Lander, A. D. (2011). Pattern, growth, and control. Cell, 144(6), 955-969. https://doi.org/10.1016/j.cell.2011.03.009

Lander, A. D., Gokoffski, K. K., Wan, F. Y., Nie, Q., \& Calof, A. L. (2009). Cell lineages and the logic of proliferative control. PLoS Biol, 7(1), e15. https://doi.org/10.1371/journal.pbio.1000015

Lee, S. J., Reed, L. A., Davies, M. V., Girgenrath, S., Goad, M. E., Tomkinson, K. N., Wright, J. F., Barker, C., Ehrmantraut, G., Holmstrom, J., Trowell, B., Gertz, B., Jiang, M. S., Sebald, S. M., Matzuk, M., Li, E., Liang, L. F., Quattlebaum, E., Stotish, R. L., \& Wolfman, N. M. (2005). Regulation of muscle growth by multiple ligands signaling through activin type II receptors. Proc Natl Acad Sci U S A, 102(50), 18117-18122. https://doi.org/10.1073/pnas.0505996102

Levine, J. H., Simonds, E. F., Bendall, S. C., Davis, K. L., Amir el, A. D., Tadmor, M. D., Litvin, O., Fienberg, H. G., Jager, A., Zunder, E. R., Finck, R., Gedman, A. L., Radtke, I., Downing, J. R., Pe'er, D., \& Nolan, G. P. (2015). Data-Driven Phenotypic Dissection of AML Reveals Progenitor-like Cells that Correlate with Prognosis. Cell, 162(1), 184-197. https://doi.org/10.1016/j.cell.2015.05.047

Michaloglou, C., Vredeveld, L. C., Soengas, M. S., Denoyelle, C., Kuilman, T., van der Horst, C. M., Majoor, D. M., Shay, J. W., Mooi, W. J., \& Peeper, D. S. (2005). BRAFE600associated senescence-like cell cycle arrest of human naevi. Nature, 436(7051), 720 724. https://doi.org/10.1038/nature03890

Neufeld, G., Mumblat, Y., Smolkin, T., Toledano, S., Nir-Zvi, I., Ziv, K., \& Kessler, O. (2016). The role of the semaphorins in cancer. Cell Adh Migr, 10(6), 652-674. https://doi.org/10.1080/19336918.2016.1197478

Nishimura, E. K., Granter, S. R., \& Fisher, D. E. (2005). Mechanisms of hair graying: incomplete melanocyte stem cell maintenance in the niche. Science, 307(5710), 720-724. https://doi.org/10.1126/science.1099593

Patton, E. E., Widlund, H. R., Kutok, J. L., Kopani, K. R., Amatruda, J. F., Murphey, R. D., Berghmans, S., Mayhall, E. A., Traver, D., Fletcher, C. D., Aster, J. C., Granter, S. R., Look, A. T., Lee, C., Fisher, D. E., \& Zon, L. I. (2005). BRAF mutations are sufficient to promote nevi formation and cooperate with p53 in the genesis of melanoma. Curr Biol, 15(3), 249-254. https://doi.org/10.1016/i.cub.2005.01.031

Pollock, P. M., Harper, U. L., Hansen, K. S., Yudt, L. M., Stark, M., Robbins, C. M., Moses, T. Y., Hostetter, G., Wagner, U., Kakareka, J., Salem, G., Pohida, T., Heenan, P., Duray, P., Kallioniemi, O., Hayward, N. K., Trent, J. M., \& Meltzer, P. S. (2003). High frequency of BRAF mutations in nevi. Nat Genet, 33(1), 19-20. https://doi.org/10.1038/ng1054

Rudolph, P., Tronnier, M., Menzel, R., Moller, M., \& Parwaresch, R. (1998). Enhanced expression of Ki-67, topoisomerase Ilalpha, PCNA, p53 and p21WAF1/Cip1 reflecting proliferation and repair activity in UV-irradiated melanocytic nevi. Hum Pathol, 29(12), 1480-1487. https://doi.org/10.1016/s0046-8177(98)90019-3

Saager, R. B., Balu, M., Crosignani, V., Sharif, A., Durkin, A. J., Kelly, K. M., \& Tromberg, B. J. (2015). In vivo measurements of cutaneous melanin across spatial scales: using multiphoton microscopy and spatial frequency domain spectroscopy. J Biomed Opt, 20(6), 066005. https://doi.org/10.1117/1.JBO.20.6.066005

Santulli, G. (2014). Angiopoietin-like proteins: a comprehensive look. Front Endocrinol (Lausanne), 5, 4. https://doi.org/10.3389/fendo.2014.00004 
Scurr, L. L., Pupo, G. M., Becker, T. M., Lai, K., Schrama, D., Haferkamp, S., Irvine, M., Scolyer, R. A., Mann, G. J., Becker, J. C., Kefford, R. F., \& Rizos, H. (2010). IGFBP7 is not required for B-RAF-induced melanocyte senescence. Cell, 141(4), 717-727. https://doi.org/10.1016/i.cell.2010.04.021

Serrano, M., Lin, A. W., McCurrach, M. E., Beach, D., \& Lowe, S. W. (1997). Oncogenic ras provokes premature cell senescence associated with accumulation of p53 and p16INK4a. Cell, 88(5), 593-602. http://www.ncbi.nlm.nih.gov/pubmed/9054499

Shain, A. H., \& Bastian, B. C. (2016). From melanocytes to melanomas. Nat Rev Cancer, 16(6), 345-358. https://doi.org/10.1038/nrc.2016.37

Swat, M. H., Thomas, G. L., Belmonte, J. M., Shirinifard, A., Hmeljak, D., \& Glazier, J. A. (2012). Multi-scale modeling of tissues using CompuCell3D. Methods Cell Biol, 110, 325-366. https://doi.org/10.1016/B978-0-12-388403-9.00013-8

Tadros, W., \& Lipshitz, H. D. (2009). The maternal-to-zygotic transition: a play in two acts. Development, 136(18), 3033-3042. https://doi.org/10.1242/dev.033183

Tran, S. L., Haferkamp, S., Scurr, L. L., Gowrishankar, K., Becker, T. M., Desilva, C., Thompson, J. F., Scolyer, R. A., Kefford, R. F., \& Rizos, H. (2012). Absence of distinguishing senescence traits in human melanocytic nevi. J Invest Dermatol, 132(9), 2226-2234. https://doi.org/10.1038/iid.2012.126

Venet, D., Dumont, J. E., \& Detours, V. (2011). Most random gene expression signatures are significantly associated with breast cancer outcome. PLoS Comput Biol, 7(10), e1002240. https://doi.org/10.1371/journal.pcbi.1002240

Vilain, R. E., McCarthy, S. W., \& Scolyer, R. A. (2016). The regenerating naevus. Pathology, 48(2), 108-112. https://doi.org/10.1016/i.pathol.2015.12.009

Vredeveld, L. C., Possik, P. A., Smit, M. A., Meissl, K., Michaloglou, C., Horlings, H. M., Ajouaou, A., Kortman, P. C., Dankort, D., McMahon, M., Mooi, W. J., \& Peeper, D. S. (2012). Abrogation of BRAFV600E-induced senescence by PI3K pathway activation contributes to melanomagenesis. Genes Dev, 26(10), 1055-1069. https://doi.org/10.1101/gad.187252.112

Wajapeyee, N., Serra, R. W., Zhu, X., Mahalingam, M., \& Green, M. R. (2008). Oncogenic BRAF induces senescence and apoptosis through pathways mediated by the secreted protein IGFBP7. Cell, 132(3), 363-374. https://doi.org/10.1016/i.cell.2007.12.032

Wiley, C. D., Flynn, J. M., Morrissey, C., Lebofsky, R., Shuga, J., Dong, X., Unger, M. A., Vijg, J., Melov, S., \& Campisi, J. (2017). Analysis of individual cells identifies cell-to-cell variability following induction of cellular senescence. Aging Cell, 16(5), 1043-1050. https://doi.org/10.1111/acel.12632

Wolf, F. A., Angerer, P., \& Theis, F. J. (2018). SCANPY: large-scale single-cell gene expression data analysis. Genome Biol, 19(1), 15. https://doi.org/10.1186/s13059-017-1382-0

Yu, Y., Schleich, K., Yue, B., Ji, S., Lohneis, P., Kemper, K., Silvis, M. R., Qutob, N., van Rooijen, E., Werner-Klein, M., Li, L., Dhawan, D., Meierjohann, S., Reimann, M., Elkahloun, A., Treitschke, S., Dorken, B., Speck, C., Mallette, F. A., Zon, L. I., Holmen, S. L., Peeper, D. S., Samuels, Y., Schmitt, C. A., \& Lee, S. (2018). Targeting the Senescence-Overriding Cooperative Activity of Structurally Unrelated H3K9 Demethylases in Melanoma. Cancer Cell, 33(2), 322-336 e328. https://doi.org/10.1016/j.ccell.2018.01.002

Zeng, H., Jorapur, A., Shain, A. H., Lang, U. E., Torres, R., Zhang, Y., McNeal, A. S., Botton, T., Lin, J., Donne, M., Bastian, I. N., Yu, R., North, J. P., Pincus, L., Ruben, B. S., Joseph, N. M., Yeh, I., Bastian, B. C., \& Judson, R. L. (2018). Bi-allelic Loss of CDKN2A Initiates Melanoma Invasion via BRN2 Activation. Cancer Cell, 34(1), 56-68 e59. https://doi.org/10.1016/j.ccell.2018.05.014

Zhang, B., Ma, S., Rachmin, I., He, M., Baral, P., Choi, S., Goncalves, W. A., Shwartz, Y., Fast, E. M., Su, Y., Zon, L. I., Regev, A., Buenrostro, J. D., Cunha, T. M., Chiu, I. M., Fisher, 
D. E., \& Hsu, Y. C. (2020). Hyperactivation of sympathetic nerves drives depletion of melanocyte stem cells. Nature, 577(7792), 676-681. https://doi.org/10.1038/s41586-0201935-3

\section{Acknowledgments}

The authors are grateful to Eric Mjolsness, Allon Klein, Randy Heiland and Paul Macklin for helpful discussions. Funding: This work was supported by National Institute of Health $(\mathrm{NIH})$ grants U54CA217378 (ADL, AG, JL). MGC was supported by NiH-T32EB009418. RRV was supported by the UC Presidents fellowship, FORD Foundation Fellowship and NIH-T32CA00905. Author Contribution: R.R.V., A.D.L., and A.K.G. conceived and designed the experiments. Multiphoton microscopy experiments were conducted by C.-F.C., P.V., T.B.K. Nest and nevus analysis were performed by R.R.V., E.R., M.G.C., H.Y., and J.L. Single cell experiments were conducted by R.R.V. and C.-F.C. and analyzed by R.R.V. and A.D.L. Human nevi were analyzed by J.S. Growth arrest models was done by M.G.C. and A.D.L. Agent based simulations were performed by R.R.V. The work was supervised by A.D.L. and A.K.G. The manuscript was written by A.D.L. and R.R.V. Declaration of interests: No conflict of interest declared by any author. Data Availability: Raw sequence data are available at GEO (Accession number TBA). 